\title{
Dissociating the influence of familiarity and meaningfulness from word frequency in naming and lexical decision performance
}

\author{
LUCIA COLOMBO \\ University of Padua, Padua, Italy \\ MARGHERITA PASINI \\ University of Verona, Verona, Italy \\ and \\ DAVID A. BALOTA \\ Washington University, St. Louis, Missouri
}

\begin{abstract}
Performance in two experiments was compared on a list of words of high and low frequency in which familiarity/meaningfulness (FM) was balanced and on a list of high- and low-frequency words in which FM was confounded with frequency (i.e., high frequency-high familiarity vs. low frequency-low familiarity). Both repetition and task (lexical decision and naming) were investigated. In the lexical decision task of Experiment 1, both frequency and repetition effects were larger in the list with FM confounded than in the list with FM matched. In the naming task, frequency and repetition effects and their interaction were significant, but there was no influence of FM list context. In Experiment 2, in which the repetitions occurred across blocks, as opposed to randomly intermixed within a list, similar results were found; however, there was no interaction between list and repetition. The results suggest that an evaluation of items in terms of their meaning and familiarity explains a large part of the variance, only in lexical decision. These dimensions may be cued both by subjective feelings of familiarity and the extent to which semantic information is available and by episodic traces due to recent encounters with the item.
\end{abstract}

The frequency of a word (i.e., the number of times a word has been encountered in spoken or written language) is one of the most investigated variables in reading and word recognition. Moreover, the interpretation of its effect is one of the most critical in the comparison of the models of word recognition. For example, it has been proposed that the lexical representations of common words require less stimulus information to be activated, either because the threshold of word detectors is lower, as in Morton's (1979) logogen model, or because the resting level of activation of the nodes for high-frequency words is higher (McClelland \& Rumelhart, 1981). Other mechanisms proposed to explain frequency effects involve search among ordered entries (Forster, 1976; Forster \& Davis, 1984) or activation and verification mechanisms (Paap, McDonald, Schvaneveldt, \& Noel, 1987; Paap, Newsome, McDonald, \& Schvaneveldt, 1982). In connectionist models (Plaut, 1997; Plaut, McClelland, Seidenberg, \& Patterson, 1996; Seidenberg \& McClelland, 1989), frequency is encoded

The research was supported by Grants FIRB 2001 to L.C. and Assegno di Ricerca 2000 to M.P. by the University of Padua. The authors thank Cristina Brivio for assistance in selecting the materials, Sandro Bettella for technical assistance, and Melvin Yap for help with the figures. Correspondence should be addressed to L. Colombo, Dipartimento di Psicologia Generale, via Venezia 8, 35131 Padova, Italy (e-mail: lucia .colombo@unipd.it). in the strength of the connection weights among units and reflects the frequency of presentation of a given pattern to the network during training. In other theoretical frameworks, frequency is assumed to influence the mapping between different representational domains, such as orthography-to-phonology and phonology-to-semantics mappings (Borowsky \& Besner, 1993; McCann \& Besner, 1987; McCann, Besner, \& Davelaar, 1988).

Frequency affects almost all tasks requiring word identification, but not to the same extent. For instance, word-frequency effects have been found to be consistently greater in lexical decision than in speeded naming (Andrews, 1982; Forster \& Chambers, 1973), suggesting that there may be some task-specific contributions to the size of the frequency effect. In addition, there is some controversy regarding the locus of the frequency effect in speeded word naming. In particular, Balota and Chumbley (1985) found some evidence that there is a word-frequency effect even when subjects have time to recognize the stimulus and simply output the recognized form (i.e., in the delayed naming condition). Hence, Balota and Chumbley argued that at least part of the frequency effect in naming could be due to processes associated with producing the response. Although this conclusion has been challenged (McRae, Jared, \& Seindenberg, 1990; Monsell, Doyle, \& Haggard, 1989), the fact that the frequency effect is smaller in nam- 
ing than in lexical decision clearly suggests that it is, to some extent, task dependent. The larger frequency effect in lexical decision has led some researchers to familiaritybased theories, according to which the large frequency effect is partly due to the importance of a familiarity/ meaningfulness (FM) evaluation (Balota \& Chumbley, 1984). High-frequency words have a very high FM value, whereas nonwords have a very low FM value, and both evaluations are made very fast. On the other hand, lowfrequency words have intermediate FM values and require a second attention-driven and slower analysis.

The effect of a global familiarity evaluation has been taken into account also in recent computational models of word recognition within the interactive activation framework (Coltheart, Rastle, Perry, Langdon, \& Ziegler, 2001; Grainger \& Jacobs, 1996). This familiarity evaluation is instantiated in a threshold that can be exceeded by the summed lexical activity of a word or nonword, leading to a fast response in lexical decision, even if no word detector has actually reached the identification threshold. Contrary to Balota and Spieler's (1999) interpretation that the familiarity evaluation is a mechanism that is emphasized in task-specific operations in lexical decision, the version of this familiarity process supported in the multiple read out model (MROM; Grainger \& Jacobs, 1996) and in the dual route cascaded (DRC) model (Coltheart et al., 2001) assumes that the global monitoring of levels or rates of activation is intrinsic to the identification process (also see Monsell et al., 1989). However, the models assume, consistent with Balota and Chumbley's position, that the mechanism producing the augmented frequency effect in lexical decision is intrinsic, and limited, to this task.

Another way to produce changes in familiarity, that has implications for the frequency effect, is through repetition of the word within the experimental context. Two classes of explanations of repetition priming effects may be distinguished. The first assumes a temporary modification to the process of lexical access. As a result of recent activation, the lexical representation of a word is left in a state of increased accessibility (Forbach, Stanners, \& Hochhaus, 1974). This type of explanation may be in agreement with activationbased models (McClelland \& Rumelhart, 1981; Morton, 1979), since it can be assumed that the lexical representations are modified after access (the word units' activation level increases, or the threshold of logogens decreases).

The second class of explanations is based on the idea that the first presentation of a word establishes an episodic memory trace that is contacted when the same word is presented again (Feustal, Shiffrin, \& Salasoo, 1983; Forster \& Davis, 1984; Jacoby \& Dallas, 1981; Logan, 1990). This view is more congruent with assumptions of lexical search theories (Becker, 1979; Forster, 1976; Murray \& Forster, 2004; Paap et al., 1982), because it does not imply a modification of lexical units on repeated presentations.

Repetition facilitates lexical decisions to low-frequency words more than to high-frequency words (Balota \& Spieler, 1999; Forster \& Davis, 1984; Scarborough, Cortese, \& Scarborough, 1977). One explanation provided for this frequency attenuation effect (Forster \& Davis, 1984) may be grounded on the interpretation of the frequency effect provided by Balota and Chumbley (1984). Within the framework of Balota and Chumbley's two-stage model of lexical decision, the FM value of an item may affect the decision stage in lexical decision: High-frequency words are more familiar, and, therefore, the latencies to classify them as words are shorter than for low-familiaritylow-frequency words. Low-frequency words are more likely to engage a second, more analytic stage and hence are more likely to benefit from a repetition, via pushing these items outside of the additional analytic check process. On the other hand, many high-frequency words do not require such a check and hence do not benefit as much as low-frequency words. Interestingly, however, this interaction does not appear if the first presentation of an item is masked, where only a short-lived frequency-insensitive repetition effect is found. To explain the different pattern of effects when the prime is masked, Forster and Davis (1984) assumed that the main effect of masking the prime is to decrease the influence of its episodic trace. Hence, Forster and Davis concluded that the frequency attenuation normally produced by repetition is due to episodic influences.

One prediction that is critical in evaluating the explanatory value of models is relative to repeated nonwords. When nonwords are repeated, their familiarity increases, leading to a bias toward a positive response, which should yield an increase in latencies and errors. Thus, familiarity theories predict an inhibitory effect of repetition priming on nonwords. Episodic memory theories make different predictions. According to Logan's $(1988,1990)$ instance theory of automatization, each event or presentation of an item leaves a trace in memory - thus, repetition priming can be conceived in terms of an association between a stimulus and its interpretation. The specific characteristics of an episode in which a word has been encountered may be a component that contributes to its identification. Thus, repetition priming for nonwords may be facilitatory if the memory trace of the former encounter, and of the interpretation associated to the stimulus, is retrieved.

Zeelenberg, Wagenmakers, and Shiffrin (2004; see also Wagenmakers, Steyvers, et al., 2004; Wagenmakers, Zeelenberg, Steyvers, Shiffrin, \& Raaijmakers, 2004) tried to distinguish the fast familiarity-based process that evaluates the global familiarity of words from the slower process that examines the interpretation (label) attached in recent encounters with a stimulus word or nonword, by considering facilitatory or inhibitory effects to nonwords. In Zeelenberg et al.'s study, when a nonword had been presented in a lexical decision task both in the study phase and in the test phase, there was a facilitatory effect of the repetition, due to the retrieval of the former encounter. When the same nonword was presented first in a letter-height study task and then in lexical decision, an inhibitory effect was found, due to the increased familiarity. Moreover, inhibition was found when both nonword presentations occurred in lexical decision, if participants 
were induced to respond very fast, congruent with the idea that the familiarity evaluation can be made quickly, whereas the retrieval of information from preceding encounters with a stimulus is relatively slower. Duchek and Neely (1989), Balota and Ferraro (1996), and Balota and Spieler (1999) also found inhibitory effects for nonword repetition under conditions in which the response to the first presentation (rhyme decisions) differed from the lexical decision. Finally, Bodner and Masson (1997) found both facilitatory and inhibitory effects of masked repetition priming on nonwords depending on whether the experimental setting did or did not favor the dominance of the familiarity mechanism.

In summary, there are a number of different processes that have been hypothesized to account for frequency and repetition priming effects, some of which reflect taskspecific operations. One process is a mechanism sensitive to the meaningfulness of a word and to the number of encounters with the underlying concept. This mechanism can be envisioned either as an independent mechanism, intrinsic to lexical decision and only to it, or as a more general process involving a global evaluation of lexical activity. The former approach suggests that the effects of familiarity would be limited to lexical decision and would not be found in other tasks. The second is a mechanism detecting an episodic trace of the former encounter with the same stimulus and of the processes involved in that encounter. We conducted the present experiments in an attempt to better understand these distinct processes.

\section{EXPERIMENT 1}

One of the aims of Experiment 1 was to separate the effects of processes specific to word identification from those involved in evaluating the global familiarity of a stimulus. In order to achieve this goal, we compared performance on a list in which FM was balanced across high- and lowfrequency words and a list in which FM was confounded with frequency (i.e., high-frequency-high-familiarity words vs. low-frequency-low-familiarity words). We used the scores on a familiarity scale as an operational definition of familiarity and the scores on an imageability scale for meaningfulness. Frequency and familiarity have a very high, but imperfect, correlation (see Balota, Pilotti, \& Cortese, 2001; Gernsbacher, 1984). Thus, frequency and FM values can be manipulated relatively independently.

The concept of familiarity is rather vague in the literature. This concept has been used with reference to how familiar a word or a concept has become due to the frequent experiences with it. However, in contrast to objective word counts, familiarity (subjective familiarity) is usually measured as scores on a scale from questionnaires investigating the subjective "feeling of familiarity," induced by the word or concept, and as such might also reflect semantic memory representations. Although objective frequency captures about $65 \%$ of the unique variance in familiarity ratings, clearly there is additional variance that is left unexplained (see Balota et al., 2001).
For example, Balota et al. (2001) found that meaningfulness (as measured by the Toglia \& Battig, 1978, norms) was more strongly related to familiarity than to objective frequency. Hence, familiarity might be sensitive to any type of representation-for example, orthographic or semantic - that participants could use in making their untimed ratings. If the cues employed by the familiarity mechanism in lexical decision are the same that produce the subjective feeling of familiarity and are reflected in familiarity ratings, they can be used to investigate the basis on which the familiarity mechanism operates in lexical decision.

Of course, when discriminating words from nonwords, in addition to the familiarity of the stimulus, another useful piece of information would be the fact that words afford meaning, whereas nonwords do not. Hence, there may be special emphasis on the meaning of the stimulus as a cue to making a lexical decision. This is precisely why Balota and Chumbley (1984) argued that meaningfulness of the stimulus is also an important dimension to consider in making lexical decisions.

Two lists of high- and low-frequency words, with varying FM values, were used in lexical decision and naming. We predicted that if lexical decision is based at least partially on the FM value of the word, then the size of the frequency effect should be smaller when the high- and low-frequency words have equivalent FM values, relative to the size of the frequency effect when the FM values are confounded (i.e., a frequency $\times$ list interaction). This manipulation was aimed at disentangling FM values from frequency. Figure 1 displays how these distributions might overlap within Balota and Chumbley's two-stage model of lexical decision. As can be seen, the low-frequency and high-frequency word distributions overlap more in the FM-matched condition than in the FM-confounded condition. Moreover, there is more overlap between the low-frequency distribution and the nonword distribution in the FM-confounded condition; hence, one would expect a slowdown in response latencies to nonwords in this condition. Since naming performance does not depend on the discrimination between familiarity and meaningful words from unfamiliar and meaningless nonwords, one would not expect an influence of the FM manipulation on naming performance.

A feeling of familiarity can also be given by recent encounters with a word, as in conditions where several presentations of the same item occur. In Experiment 1, we tested the repetition priming effect by presenting the same stimulus twice, in mixed order. We predicted a frequency $X$ repetition priming interaction, with low-frequency words producing particularly fast response latencies on the second presentation, relative to high-frequency words. If repetition interacts also with the FM list manipulation, this would suggest that the repetition effect is based, at least partially, on the same dimension of familiarity that produces the subjective familiarity evaluation, as opposed to a mechanism retrieving episodic traces from memory (episodic familiarity). 

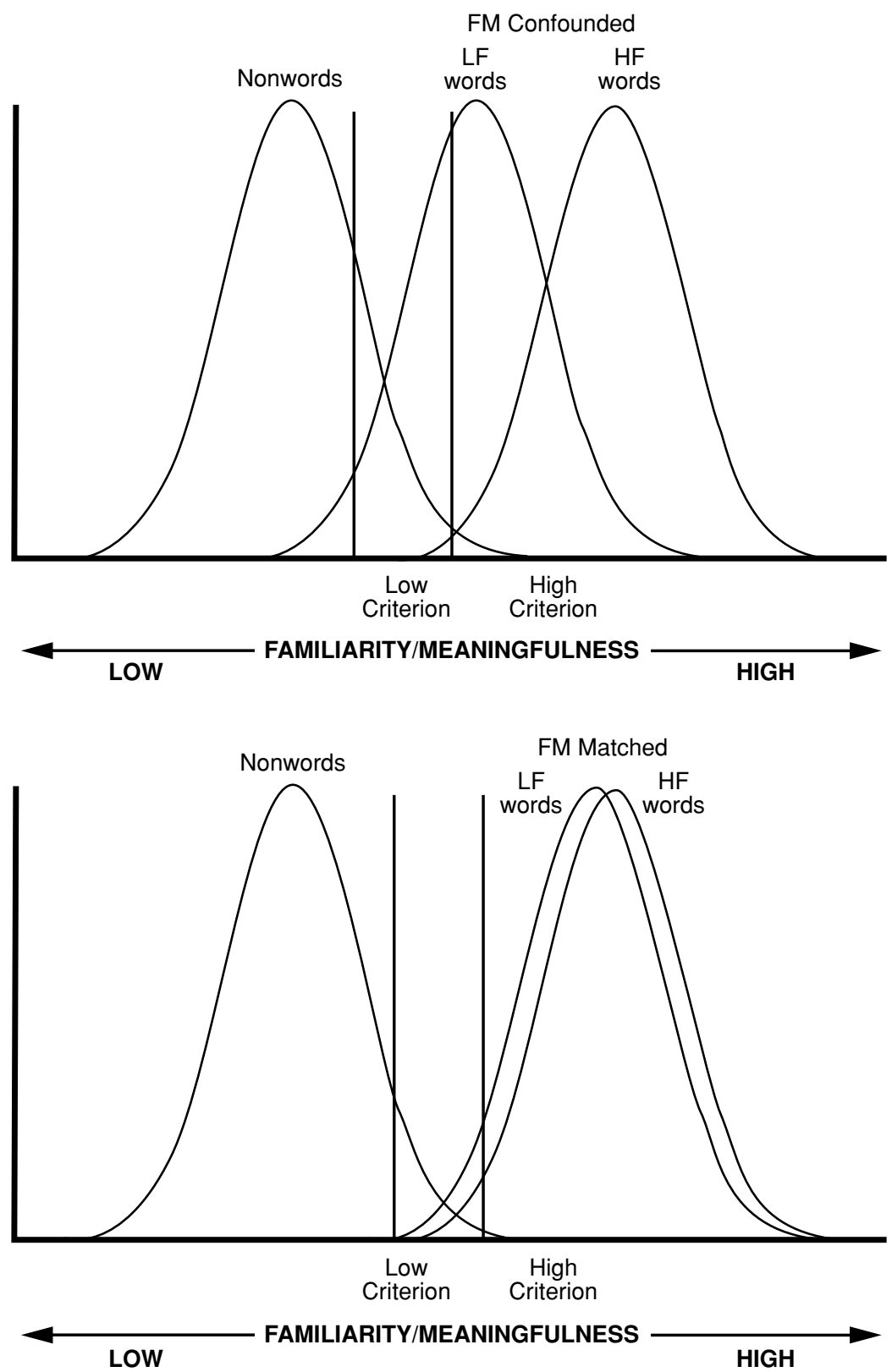

Figure 1. The response time distributions for high- and low-frequency words and nonwords, with familiarity and imageability matched (FM matched) or confounded (FM confounded).

Assuming that repetition priming for nonwords is facilitatory in the conditions of the present experiment (Zeelenberg et al., 2004; see above), there should be a smaller repetition effect for nonwords when familiarity is confounded than when familiarity is equated. Of course, we are also interested in the frequency $\times$ repetition $\times$ list manipulation in naming performance, where it is assumed that the subjective familiarity evaluation should provide relatively little help in converting print to sound. Thus, we expected that if the effect of the list is mediated by a familiarity mechanism specific to lexical decision, as as- sumed by Balota and Spieler (1999), it should be apparent only in lexical decision, not in naming.

\section{Method}

Participants. One hundred fifty-five students from the University of Padua with normal or corrected-to-normal vision participated in the experiment. For the lexical decision task, 39 participants were in the FM-matched condition and 39 were in the FM-confounded condition. For the naming task, 38 participants were in the FMmatched condition and 39 were in the FM-confounded condition.

Materials. The word stimuli were selected to conform to a factorial manipulation of word frequency (high/low) and list type, with 
FM matched or confounded. Two sets of 21 words each - one with high-frequency words, and one with low-frequency words-were selected. The frequency was taken from a frequency count based on a written corpus of 1,500,000 occurrences (Istituto di Linguistica Computazionale del CNR di Pisa, 1989). The two lists of words were matched on a number of lexical and sublexical values: age of acquisition, concreteness, neighborhood size, bigram frequency, and length in syllables and in letters. An attempt was made to match words on lexical stress and on word initial phoneme (classified as voiced vs. voiceless, and for manner of articulation). In the list with FM-confounded values, high-frequency words also had high values on the subjective familiarity and imageability variables (see Table 1), and low-frequency words were low in familiarity and imageability. Another list with two sets of 21 words was selected for the FM-matched list condition, with high- and low-frequency words matched on familiarity and imageability (see Table 2). The values of the variables were taken from Barca, Burani, and Arduino's (2002) database (available also in www.istc.ip.rm.cnr.it/material/database/ lexvar.htm), in which familiarity was tested by presenting participants with written words and asking them to evaluate the familiarity of the underlying concept. Forty-two nonwords were constructed for use in the lexical decision task. The nonwords were orthographically and phonologically legal and matched the letter length and syllable length of the word lists.

Procedure. Each stimulus was presented on a computer monitor, using a reaction time measurement program (Psychology Software Tools, Micro Experimental Laboratory software). Six lists were constructed with items in a different pseudorandom order (to avoid successive repetition of the same items). Between repeated items, there were 1-41 items. For lexical decision, each list included 42 words and 42 nonwords. Six new items (three nonwords and three words) were used for practice. The participants were told that their task was to decide as quickly and as accurately as possible whether each item was a real Italian word and to respond as quickly as possible to each item by pressing the " $\mathrm{M}$ " key and the " $\mathrm{C}$ " key for positive and negative responses, respectively. A $500-\mathrm{msec}$ tone was produced as feedback after incorrect responses. Each stimulus was preceded by a central fixation asterisk, which remained on the screen for $500 \mathrm{msec}$, followed by a blank 300 -msec interval. The task took approximately $10 \mathrm{~min}$.

For the naming task, the same materials were presented, without the nonwords. Thus, between repeated items, there were 1-12 items (because nonwords were not presented). The participants were told that their task was to name the words aloud as quickly and as accurately as possible. They were instructed to avoid making any extraneous noises that might trigger the voice key. Each stimulus was preceded by a central fixation asterisk, which remained on the screen for $500 \mathrm{msec}$, followed by a blank $300-\mathrm{msec}$ interval. After each naming response, the experimenter pressed a key to present the next word. The experimenter coded the response as correct, error (mispronunciation), or voice-key error (i.e., an extraneous sound triggered the voice key), via the keyboard. The task took approximately $8 \mathrm{~min}$.

\section{Results}

Lexical decision. The dependent variables were the mean response times (RTs) for participants and items. Mean correct responses and errors were calculated for each condition. RTs that fell above or below 3 standard deviations $(S D \mathrm{~s})$ from the participant mean were excluded from the analyses. For words, $0.5 \%$ of the RTs were removed; for nonwords, $1.5 \%$ were removed. Mean RTs and errors are displayed in Table 3. Given that the pattern of errors was congruent with that of RTs and that errors were few, no analyses of errors are reported.

We ran analyses of RTs with participants and items as random factors. In the analysis with participants as random factor $\left(F_{1}\right)$, the experimental design consisted of frequency and repetition (first and second presentation) as within-participants factors, and list (FM matched and FM confounded) as a between-participants factor. In the analysis with items as random factor $\left(F_{2}\right)$, frequency and list were between-items factors, and repetition was a within-items factor.

As predicted, there was a reliable effect of the list manipulation. The frequency effect was larger in the list with frequency and FM confounded, relative to the list with FM balanced. The ANOVA on the RTs produced main effects of repetition $\left[F_{1}(1,77)=201.96, M S_{\mathrm{e}}=861.39, p<\right.$ $\left..001 ; F_{2}(1,80)=155.13, M S_{\mathrm{e}}=682.10, p<.001\right]$, and frequency $\left[F_{1}(1,77)=75.56, M S_{\mathrm{e}}=1,055.78, p<.001\right.$; $\left.F_{2}(1,80)=28.31, M S_{\mathrm{e}}=2,100.73, p<.001\right]$. Frequency interacted with repetition $\left[F_{1}(1,77)=34.65, M S_{\mathrm{e}}=\right.$ $584.75, p<.001 ; F_{2}(1,80)=20.53, M S_{\mathrm{e}}=682.10$, $p<.001$ ], with a smaller frequency effect in the second presentation. Crucially, there was a frequency $\times$ list interaction $\left[F_{1}(1,77)=32.11, M S_{\mathrm{e}}=1,055.78, p<.001\right.$;

Table 1

Mean Values and Standard Deviations for the Variables of Words in the FM-Matched Condition From Barca, Burani, and Arduino's (2002) Database

\begin{tabular}{|c|c|c|c|c|c|}
\hline \multirow[b]{2}{*}{ Lexical and Sublexical Variables } & \multicolumn{2}{|c|}{ HF Words } & \multicolumn{2}{|c|}{ LF Words } & \multirow{2}{*}{$\begin{array}{c}p \text { Value for } \\
\text { the } t \text { Test }\end{array}$} \\
\hline & $M$ & $S D$ & $M$ & $S D$ & \\
\hline Age of acquisition & 2.82 & 0.65 & 2.83 & 0.70 & n.s. \\
\hline Bigram frequency & 10.89 & 0.33 & 10.72 & 0.38 & n.s. \\
\hline Concreteness & 5.54 & 1.16 & 5.93 & 0.99 & n.s. \\
\hline Familiarity & 6.70 & 0.21 & 6.66 & 0.18 & n.s. \\
\hline Imageability & 5.58 & 0.77 & 5.79 & 0.67 & n.s. \\
\hline Length in letters & 7.05 & 0.92 & 6.76 & 0.83 & n.s. \\
\hline Length in syllables & 3.00 & 0.00 & 3.00 & 0.00 & n.s. \\
\hline Mean word naming time & 518 & 21.34 & 538 & 25.12 & $<.001$ \\
\hline Neighborhood size & 0.43 & 0.75 & 0.24 & 0.54 & n.s. \\
\hline Word frequency (adult spoken) & 42.10 & 38.79 & 2.38 & 3.35 & $<.01$ \\
\hline Word frequency (adult written) & 206.95 & 104.51 & 13.95 & 7.96 & $<.001$ \\
\hline Word frequency (child written) & 269.52 & 282.15 & 45.38 & 37.07 & $<.001$ \\
\hline
\end{tabular}

Note-FM, familiarity/meaningfulness; HF, high frequency; LF, low frequency. 
Table 2

\begin{tabular}{|c|c|c|c|c|c|}
\hline \multirow[b]{2}{*}{ Lexical and Sublexical Variables } & \multicolumn{2}{|c|}{ HF Words } & \multicolumn{2}{|c|}{ LF Words } & \multirow{2}{*}{$\begin{array}{c}p \text { Value for } \\
\text { the } t \text { Test }\end{array}$} \\
\hline & $M$ & $S D$ & $M$ & $S D$ & \\
\hline Age of acquisition & 3.45 & 0.86 & 3.55 & 0.70 & n.s. \\
\hline Bigram frequency & 10.80 & 0.44 & 10.67 & 0.36 & n.s. \\
\hline Concreteness & 5.24 & 0.98 & 5.50 & 0.98 & n.s. \\
\hline Familiarity & 6.59 & 0.40 & 5.38 & 0.70 & $<.001$ \\
\hline Imageability & 5.40 & 0.80 & 4.71 & 0.93 & $<.05$ \\
\hline Length in letters & 6.14 & 1.24 & 5.95 & 1.47 & n.s. \\
\hline Length in syllables & 2.62 & 0.67 & 2.57 & 0.68 & n.s. \\
\hline Mean word naming time & 521 & 24.15 & 536 & 30.09 & .085 \\
\hline Neighborhood size & 1.14 & 1.39 & 1.38 & 2.27 & n.s. \\
\hline Word frequency (adult spoken) & 60.14 & 70.89 & 0.95 & 2.71 & $<.01$ \\
\hline Word frequency (adult written) & 291.52 & 219.50 & 13.86 & 17.23 & $<.001$ \\
\hline Word frequency (child written) & 210.57 & 270.53 & 22.00 & 31.78 & $<.01$ \\
\hline
\end{tabular}

Note-FM, familiarity/meaningfulness; HF, high frequency; LF, low frequency.

$\left.F_{2}(1,80)=11.89, M S_{\mathrm{e}}=2,100.73, p<.01\right]$, which reflected the fact that the frequency effect was only $11 \mathrm{msec}$ in the FM-matched list and was $53 \mathrm{msec}$ in the FMconfounded condition. List interacted also with repetition $\left[F_{1}(1,77)=7.29, M S_{\mathrm{e}}=861.39, p<.01 ; F_{2}(1,80)=\right.$ $\left.6.45, M S_{\mathrm{e}}=682.10, p<.05\right]$, which reflected a smaller repetition effect in the FM-matched list. Finally, the threeway interaction was marginally significant $\left[F_{1}(1,77)=\right.$ $3.41, M S_{\mathrm{e}}=584.75, p<.1 ; F_{2}(1,80)=2.99, M S_{\mathrm{e}}=$ $662.10, p<.1]$. As shown in Table 3 , the data of the lexical decision experiment showed a decrease in the size of the repetition effect in the FM-matched list relative to the FM-confounded list for low-frequency words $\left[F_{1}(1,77)=\right.$ $7.74, M S_{\mathrm{e}}=991.70, p<.01 ; F_{2}(1,40)=7.0, M S_{\mathrm{e}}=$ $888.06, p<.05$ ], but there was no list $\times$ repetition interaction for high-frequency words $\left[F_{1}(1,77)=1.31, p>\right.$ $\left.1 ; F_{2}<1\right]$.

Nonwords. The ANOVA on the nonword RTs was run with repetition as a within-participants factor and list as a between-participants factor. As shown in Table 4, there was a facilitatory repetition effect $\left[F_{1}(1,77)=134.67\right.$, $M S_{\mathrm{e}}=1,017.09, p<.001 ; F_{2}(1,41)=112.52, M S_{\mathrm{e}}=$ $1,447.77, p<.001]$. The list effect was marginally significant only by items $\left[F_{2}(1,41)=3.62, M S_{\mathrm{e}}=738.02, p<\right.$ .1]. More importantly, as predicted, there was a significant list $\times$ repetition interaction $\left[F_{1}(1,77)=4.02, M S_{\mathrm{e}}=\right.$ $1,017.09, p<.05 ; F_{2}(1,41)=3.74, M S_{\mathrm{e}}=969.18 . p<$ $.1]$, which reflected a smaller repetition advantage for the second presentation for nonwords in the FM-confounded list condition (48 $\mathrm{msec}$ ) than in the FM-matched list condition (69 msec).

Naming. The RTs above or below $3 \mathrm{SDs}$ from each participant's mean were removed from further analyses $(0.6 \%)$. The mean correct RTs and errors are shown in Table 5. RTs to repeated words were faster than those to unrepeated words $\left[F_{1}(1,76)=144.51, M S_{\mathrm{e}}=510.77\right.$, $\left.p<.001 ; F_{2}(1,80)=162.96, M S_{\mathrm{e}}=246.39, p<.001\right]$, and RTs to high-frequency words were faster than those to low-frequency words $\left[F_{1}(1,76)=112.08, M S_{\mathrm{e}}=496.18\right.$, $\left.p<.001 ; F_{2}(1,80)=11.09, M S_{\mathrm{e}}=2,692.70, p<.01\right]$. Frequency interacted with repetition $\left[F_{1}(1,76)=34.98\right.$,
$M S_{\mathrm{e}}=270.67, p<.001 ; F_{2}(1,80)=18.75, M S_{\mathrm{e}}=$ $246.39, p<.001]$, reflecting a smaller advantage for high-frequency repeated words $(22 \mathrm{msec})$ than for lowfrequency words $(42 \mathrm{msec})$. There was also an interaction of list with frequency $\left[F_{1}(1,76)=7.79, M S_{\mathrm{e}}=496.18\right.$, $\left.p<.01 ; F_{2}(1,80)=3.28, M S_{\mathrm{e}}=246.39, p<.1\right]$, only by participants, which, in contrast to the lexical decision task, reflected a slightly larger frequency effect in the FMmatched list than in the FM-confounded list.

\section{Discussion}

The results of Experiment 1 largely supported the predictions related to the list manipulation: When items were matched on FM, the frequency effect in lexical decision decreased substantially, confirming the hypothesis that a global FM evaluation was used in the discrimination between words and nonwords. In addition, there was evidence of a larger repetition effect for the FM-confounded condition than for the FM-balanced condition. This latter effect was predicted because the overlap between words and nonwords was greater in the FM-confounded condition, and hence the benefit of repetition was expected to

Table 3

Mean Response Times (RTs, in Milliseconds) and Errors (in Proportions) on Correct Lexical Decisions for High-Frequency (HF) and Low-Frequency (LF) Words in the FM-Matched and FM-Confounded Conditions of Experiment 1 (Mixed Repetitions)

\begin{tabular}{|c|c|c|c|c|c|c|}
\hline \multirow[b]{2}{*}{ Presentation } & \multicolumn{3}{|c|}{ FM Matched } & \multicolumn{3}{|c|}{ FM Confounded } \\
\hline & $\mathrm{HF}$ & LF & $\begin{array}{c}\text { Frequency } \\
\text { Effect }\end{array}$ & $\mathrm{HF}$ & LF & $\begin{array}{c}\text { Frequency } \\
\text { Effect }\end{array}$ \\
\hline \multicolumn{7}{|l|}{ First } \\
\hline RT & 576 & 598 & -22 & 569 & 642 & -73 \\
\hline Error & .03 & .05 & -.02 & .04 & .13 & -.09 \\
\hline \multicolumn{7}{|l|}{ Second } \\
\hline RT & 549 & 549 & 0 & 534 & 566 & -32 \\
\hline Error & .01 & .02 & -.01 & .01 & .02 & -.01 \\
\hline \multicolumn{7}{|c|}{ Repetition Effect } \\
\hline & 27 & 49 & & 35 & 76 & \\
\hline
\end{tabular}

Note-FM, familiarity/meaningfulness. 
Table 4

Mean Response Times (RTs, in Milliseconds) and Errors (in Proportions) on Correct Lexical Decisions for Nonwords in the FM-Matched and FM-Confounded Conditions of Experiment 1 (Mixed Repetitions)

\begin{tabular}{cccc}
\hline Presentation & FM Matched & FM Confounded & List Effect \\
\hline First & & & \\
RT & 686 & 683 & 3 \\
Error & .06 & .06 & .00 \\
Second & & & \\
RT & 617 & 635 & -18 \\
Error & .04 & .05 & -.01 \\
& \multicolumn{2}{c}{ Repetition Effect } \\
\end{tabular}

Note-FM, familiarity/meaningfulness.

be greater. Turning to the nonwords, the advantage of repetition was decreased in the FM-confounded condition, which is also consistent with the predictions. Specifically, repeating nonwords produced an increase in stimulus familiarity, which decreased the advantage of repeating the response and decision (see Zeelenberg et al., 2004).

The naming data yielded a frequency $\times$ repetition interaction that reflected larger frequency effects on the first presentation than on the second presentation. This pattern was not obtained by Balota and Spieler (1999), but they manipulated repetition in a different manner. In their Experiment 2, the first encounter of each word was in a rhyming task, and the second presentation was within a naming task in the second phase of the experiment. Moreover, both words and nonwords were presented in both phases of the experiment. Hence, it is possible that this may have led to an enhancement of the sublexical processes in the naming task. Indeed, they reported very small frequency effects for words, which reliably increased in a third experiment that excluded the first rhyming phase of the experiment.

The naming data of the present experiment actually showed a slight tendency (reliable by participants but not by items) for a larger frequency effect in the FM-matched conditions than in the FM-confounded conditions. This is in sharp contrast to the lexical decision data and is important because these data clearly indicate that the listmodulated frequency effect in the lexical decision task is not due to the selection of relatively lower frequency words in the FM-confounded condition because of poor frequency estimates. Moreover, these results suggest that the emphasis on FM information is specific to the operations involved in lexical decision, as opposed to general operations involved in lexical access.

\section{EXPERIMENT 2}

In Experiment 1, the first and second presentations of each stimulus were randomly spread within the experiment. One might argue that the frequency reduction in the FM-matched list might have been somehow induced or increased by the intermixing of repeated and unrepeated stimuli. That is, because the participants were exposed to the first and second encounters within the same list, it is possible that this increased the reliance on FM information. Hence, the modulation of the word-frequency effect by the list manipulation may occur only when participants emphasize familiarity induced by episodic retrieval in making their lexical decisions. In Experiment 2, we separated the influence of repetition from the influence of list. Specifically, all items were first presented in Block 1 and then were repeated in Block 2. Effects of the list manipulation in the first presentation of the stimuli (first block) could then be attributed solely to the subjective familiarity of each item, as opposed to increased emphasis of subjective familiarity due to the importance of episodic retrieval.

\section{Method}

Participants. One hundred thirty-four students with normal or corrected-to-normal vision participated in the experiment. Thirty participants performed the lexical decision task in the FM-matched condition, and 37 performed it in the FM-confounded condition. Thirty performed the naming task in the FM-matched condition, and 36 performed it in the FM-confounded condition.

Procedure. The procedure was the same as that in the lexical decision and naming tasks of Experiment 1, except that the word list (and nonword list for lexical decision) was presented once in the first block and, after a short interval, was presented a second time in a differently randomized order.

\section{Results}

Lexical decision. The latencies on trials where participants made errors and those that fell above or below $3 \mathrm{SDs}$ were dropped from the analyses. These criteria eliminated $0.8 \%$ of the observations for words and $1.4 \%$ for nonwords. As in Experiment 1, the analyses of errors are not reported. Table 6 shows the mean RTs for each condition. High-frequency words were recognized faster than were low-frequency words $\left[F_{1}(1,65)=95.94, M S_{\mathrm{e}}=1,385.8\right.$, $\left.p<.001 ; F_{2}(1,80)=39.74, M S_{\mathrm{e}}=2,887.43, p<.001\right]$. The main effect of repetition was significant, with the first presentation slower than the second one $\left[F_{1}(1,65)=17.65\right.$, $M S_{\mathrm{e}}=3,355.88, p<.001 ; F_{2}(1,80)=71.24, M S_{\mathrm{e}}=$

Table 5

Mean Response Times (RTs, in Milliseconds) and Errors (in Proportions) on Correct Word Naming for High-Frequency (HF) and Low-Frequency (LF) Words in the FM-Matched and FM-Confounded Conditions of Experiment 1 (Mixed Repetitions)

\begin{tabular}{|c|c|c|c|c|c|c|}
\hline \multirow[b]{2}{*}{ Presentation } & \multicolumn{3}{|c|}{ FM Matched } & \multicolumn{3}{|c|}{ FM Confounded } \\
\hline & $\mathrm{HF}$ & $\mathrm{LF}$ & $\begin{array}{c}\text { Frequency } \\
\text { Effect }\end{array}$ & $\mathrm{HF}$ & LF & $\begin{array}{c}\text { Frequency } \\
\text { Effect }\end{array}$ \\
\hline \multicolumn{7}{|l|}{ First } \\
\hline RT & 493 & 539 & -46 & 513 & 542 & -29 \\
\hline Error & .01 & .01 & .00 & .01 & .04 & -.03 \\
\hline \multicolumn{7}{|l|}{ Second } \\
\hline RT & 479 & 500 & -21 & 488 & 498 & -10 \\
\hline Error & .00 & .00 & .00 & .00 & .00 & .00 \\
\hline \multicolumn{7}{|c|}{ Repetition Effect } \\
\hline & 14 & 39 & & 25 & 44 & \\
\hline
\end{tabular}

Note-FM, familiarity/meaningfulness. 
Table 6

Mean Response Times (RTs, in Milliseconds) and Errors (in Proportions) on Correct Lexical Decisions for High-Frequency (HF) and Low-Frequency (LF) Words in the FM-Matched and FM-Confounded Conditions of Experiment 2 (Blocked Repetitions)

\begin{tabular}{|c|c|c|c|c|c|c|}
\hline \multirow[b]{2}{*}{ Presentation } & \multicolumn{3}{|c|}{ FM Matched } & \multicolumn{3}{|c|}{ FM Confounded } \\
\hline & $\mathrm{HF}$ & LF & $\begin{array}{c}\text { Frequency } \\
\text { Effect }\end{array}$ & $\mathrm{HF}$ & LF & $\begin{array}{c}\text { Frequency } \\
\text { Effect }\end{array}$ \\
\hline \multicolumn{7}{|l|}{ First } \\
\hline RT & 603 & 639 & -36 & 604 & 684 & -80 \\
\hline Error & .02 & .05 & -.03 & .03 & .09 & -.06 \\
\hline \multicolumn{7}{|l|}{ Second } \\
\hline RT & 586 & 600 & -14 & 588 & 637 & -49 \\
\hline Error & .01 & .04 & -.03 & .01 & .06 & -.05 \\
\hline \multicolumn{7}{|c|}{ Repetition Effect } \\
\hline & 17 & 39 & & 16 & 47 & \\
\hline
\end{tabular}

Note_FM, familiarity/meaningfulness.

$644.89, p<.001]$. In the analysis by items, the main effect of list was significant, with RTs in the FM-confounded condition slower than those in the FM-matched condition $\left[F_{2}(1,80)=10.62, M S_{\mathrm{e}}=2,887.43, p<.01\right]$. The interaction between frequency and repetition was significant, as reflected by a larger difference between high-frequency and low-frequency words on the first presentation than on the second presentation $\left[F_{1}(1,65)=20.81, M S_{\mathrm{e}}=553.49\right.$, $\left.p<.001 ; F_{2}(1,80)=15.55, M S_{\mathrm{e}}=644.89, p<.001\right]$. As in Experiment 1, the crucial interaction between frequency and list was significant, with the frequency effect larger in the FM-confounded condition $(76 \mathrm{msec})$ than in the FMmatched condition $(26 \mathrm{msec})\left[F_{1}(1,65)=17.82, M S_{\mathrm{e}}=\right.$ $1,385.80, p<.001 ; F_{2}(1,80)=7.56, M S_{\mathrm{e}}=2,887.43, p<$ $.01]$. Neither the list $\times$ repetition interaction nor the threeway interaction was significant (both $F_{\mathrm{S}}<1$ ). Importantly, the analysis of the RTs in the first block, where the episodic mechanism was not involved, showed reliable effects of both frequency $\left[F_{1}(1,65)=81.81, M S_{\mathrm{e}}=1,361.25, p<\right.$ $\left..001 ; F_{2}(1,80)=44.94, M S_{\mathrm{e}}=2,142.79, p<.001\right]$ and its interaction with list $\left[F_{1}(1,65)=11.11, M S_{\mathrm{e}}=1,361.25\right.$, $\left.p<.001 ; F_{2}(1,80)=6.41, M S_{\mathrm{e}}=2,142.79, p<.05\right]$.

Nonwords. The ANOVA on RTs for nonwords (see Table 7) showed an effect of repetition $\left[F_{1}(1,65)=47.67\right.$, $M S_{\mathrm{e}}=3,919.26, p<.001 ; F_{2}(1,41)=222.54, M S_{\mathrm{e}}=$ $1,107.95, p<.001]$, with RTs to nonwords faster on the first presentation, and an effect of list $\left[F_{1}(1,65)=\right.$ $3.45, M S_{\mathrm{e}}=22,380.27, p<.1 ; F(1,41)=9.63, M S_{\mathrm{e}}=$ $6,461.95, p<.05]$, with RTs to nonwords faster in the FM-matched list. The interaction was not significant $(F<1)$.

Naming. Table 8 displays the mean RTs and error percentage for each condition. The discarded trials, following the criteria for the naming task in Experiment 1, were $0.5 \%$ of the observations. The frequency effect $\left[F_{1}(1,64)=93.57, M S_{\mathrm{e}}=378.08, p<.001 ; F_{2}(1,80)=\right.$ $\left.9.49, M S_{\mathrm{e}}=2,531.83, p<.01\right]$ and the repetition effect $\left[F_{1}(1,64)=77.19, M S_{\mathrm{e}}=1,506.06, p<.001 ; F_{2}(1,80)=\right.$ $\left.227.05, M S_{\mathrm{e}}=344.99, p<.001\right]$ were significant. The interaction between frequency and repetition was signifi- cant, with a larger frequency effect in the first presentation condition than in the second presentation condition $\left[F_{1}(1,64)=19.64, M S_{\mathrm{e}}=211.59, p<.001 ; F_{2}(1,80)=\right.$ $\left.8.15, M S_{\mathrm{e}}=344.99, p<.05\right]$.

There was a main effect of the list, only marginal by participants, with RTs for the FM-confounded condition slower than for the FM-matched condition $\left[F_{1}(1,64)=\right.$ $3.44, M S_{\mathrm{e}}=24,862.03, p<.1 ; F_{2}(1,80)=21.49, M S_{\mathrm{e}}=$ $2,531.83, p<.001]$. Crucially, the frequency $\times$ list interaction that was significant in lexical decision again failed to approach significance (both $F \mathrm{~s}<1$ ).

\section{Discussion}

The results of Experiment 2 suggest that the attempt to disentangle effects of the FM value from those produced by inclusion of repetitions within the same list was successful. Specifically, when considering only the data of Block 1, in which there was no repetition, there was a 44msec reduction of the frequency effect in the FM-matched condition, relative to the FM-confounded condition. This finding indicates that the participants relied on an evaluation of the FM value en route to making their lexical decisions. Moreover, neither the list $\times$ repetition interaction nor the three-way interaction was significant, suggesting that different processes prevailed in this experiment, unlike in Experiment 1. Because of the relatively short lags in Experiment 1, and the mixing of repeated and nonrepeated stimuli, lexical decisions might have been more influenced by the direct retrieval of stimulus-response associations, which produced a perceived change in the familiarity of the stimulus, thereby producing the list $\times$ repetition interaction. In contrast, in Experiment 2, repetition occurred at longer lags and only in the second block in which all stimuli (both words and nonwords) were repeated. Hence, this would decrease the influence of repetition and therefore decrease the likelihood of a repetition $\times$ list interaction.

In order to see whether changes in lags and repetition blocking would have produced a different pattern of results, we examined the RTs in Experiment 1 for those items for which the repetitions occurred at long lags. If the pattern obtained in Experiment 2 was due to generally longer

Table 7

Mean Response Times (RTs, in Milliseconds) and Errors (in Proportions) on Correct Lexical Decisions for Nonwords in the FM-Matched and FM-Confounded Conditions of Experiment 2 (Blocked Repetitions)

\begin{tabular}{cccc}
\hline Presentation & FM Matched & FM Confounded & List Effect \\
\hline First & 742 & 781 & -39 \\
RT & .06 & .04 & .02 \\
Error & 667 & 706 & -39 \\
Second & .04 & .03 & .01 \\
RT & \multicolumn{2}{c}{ Repetition Effect } \\
Error & 75 & 75 & \\
& 75
\end{tabular}

Note_FM, familiarity/meaningfulness. 
Table 8

Mean Response Times (RTs, in Milliseconds) and Errors (in Proportions) on Correct Word Naming for High-Frequency

(HF) and Low-Frequency (LF) Words in the FM-Matched and FM-Confounded Conditions of Experiment 2 (Blocked Repetitions)

\begin{tabular}{|c|c|c|c|c|c|c|}
\hline \multirow[b]{2}{*}{ Presentation } & \multicolumn{3}{|c|}{ FM Matched } & \multicolumn{3}{|c|}{ FM Confounded } \\
\hline & $\mathrm{HF}$ & LF & $\begin{array}{c}\text { Frequency } \\
\text { Effect }\end{array}$ & $\mathrm{HF}$ & LF & $\begin{array}{c}\text { Frequency } \\
\text { Effect }\end{array}$ \\
\hline \multicolumn{7}{|l|}{ First } \\
\hline RT & 510 & 538 & -28 & 546 & 579 & -33 \\
\hline Error & .00 & .01 & -.01 & .01 & .03 & -.02 \\
\hline \multicolumn{7}{|l|}{ Second } \\
\hline RT & 475 & 493 & -18 & 512 & 524 & -12 \\
\hline Error & .00 & .00 & .00 & .00 & .00 & .00 \\
\hline \multicolumn{7}{|c|}{ Repetition Effect } \\
\hline & 35 & 45 & & 34 & 55 & \\
\hline
\end{tabular}

Note_FM, familiarity/meaningfulness.

lags, in the following analyses we should find results similar to those obtained in Experiment 2. Words were divided in two groups, short and long lag, on the basis of the median of the distance between first and second presentation of the same word. In the FM-matched list, distances ranged from 1 to 23 items, so distances from 12 to 23 items were classified as long lags. In the FM-confounded list, the range was from 1 to 26 items, so 14-26 items were considered long lags. There were 15 long-lag items in the FM-matched list and 16 in the FM-confounded list. The ANOVA by items, with repetition, frequency, and list as factors, replicated the pattern found with the whole data: a significant effect of repetition $\left[F(1,27)=38.34, M S_{\mathrm{e}}=\right.$ $755.91, p<.001]$ and frequency $[F(1,27)=12.47$, $\left.M S_{\mathrm{e}}=1,910.53, p<.01\right]$ and a marginally reliable effect of list $\left[F(1,27)=3.29, M S_{\mathrm{e}}=1,910.53, p<.1\right]$. There were also reliable interactions between list and frequency $\left[F(1,27)=4.53, M S_{\mathrm{e}}=1,910.53, p<.05\right]$, repetition and list $\left[F(1,27)=10.04, M S_{\mathrm{e}}=755.91, p<.01\right]$, and repetition and frequency $\left[F(1,27)=8.55, M S_{\mathrm{e}}=755.91, p<\right.$ $.01]$. Given the similarity of the results of the analyses on these long-lag items with the overall analyses of Experiment 2, it seems unlikely that the results of Experiment 1 were due to longer distances between presentations.

Further information can be gathered by the pattern of results on nonwords. Nonwords were faster on the FM-matched list, since their discrimination from lowfrequency words was easier in this condition, and they were faster on the second presentation, presumably because the former traces of the encounter with the same nonword were retrieved, but there was no interaction (no decrease in the size of the list effect in the second presentation), suggesting that subjective and episodic familiarity were separated in this experiment.

The data of the naming task are equally clear. Both frequency and repetition were significant, as was their interaction. Although naming RTs were faster in the FMmatched list, the size of the list effect was about the same for high- and low-frequency words (i.e., there was no hint of a list $X$ frequency interaction). Of course, this task dif- ference was expected. Specifically, in lexical decision, words must be discriminated from nonwords, and the decision on low-frequency words was easier when they were familiar, which led to the list $x$ frequency interaction. However, naming involves retrieving the pronunciation for an orthographic input, and so FM information is relatively unimportant.

\section{GENERAL DISCUSSION}

In the literature on word recognition, a number of researchers (Balota \& Chumbley, 1984; Besner \& Swan, 1982; Grainger \& Jacobs, 1996) have provided evidence that an evaluation of familiarity is part of the process that leads to lexical identification somewhat independently of the processes that are sensitive to frequency. The manner in which this evaluation process has been conceived is different across the theories. In the two-stage model proposed by Balota and Chumbley (1984), it is conceived as an evaluation of the global FM of a stimulus. When the FM value is very high or low (very familiar words and nonwords), the criterion for response is reached quickly, and a fast positive or negative response is given. When the criterion is not reached, a more attention-driven process presumably is engaged. According to this account, the large size of the frequency effect in the lexical decision task, relative to naming, for example, derives partly from this dissociation between the two processes. In Balota and Chumbley (1984; Balota \& Spieler, 1999), the FM evaluation was specific to lexical decision. However, Monsell et al. (1989) challenged this assumption, claiming instead that the familiarity evaluation process is monitoring the global lexical activity going on when a word/nonword stimulus is presented (also see Andrews \& Heathcote, 2001). Thus, the size of the frequency effect is not just artificially large in lexical decision, but rather it is smaller in a task such as naming due to another type of process involved in this task - the assembly process - that is not sensitive to lexical variables. Computational models, such as Grainger and Jacobs's (1996) MROM and the DRC model (Coltheart et al., 2001), also include a process sensitive to the global activity in the lexicon but assume that it is specific to lexical decision.

The results of the present study appear most consistent with the model proposed by Balota and Spieler (1999), showing that a mechanism evaluating familiarity is responsible for the inflation in the size of the frequency effect. Specifically, the frequency effect was much larger when FM values were confounded than when FM values were matched. This interpretation of the list $\times$ frequency manipulation appears even more clear when compared with the data of the naming task. In contrast to lexical decision, the frequency effect did not decrease in the FMmatched list in naming (actually, there was a small difference in the opposite direction, though only reliable by participants). This is consistent with the argument that the naming task does not rely heavily on an FM signal to drive the response; rather, mere frequency of exposure and production are more important. 
As noted in the introduction, the FM variable was manipulated in the present study by using ratings of familiarity and imageability. Thus, these variables were totally confounded in the present study. This raises the question of which one of the two variables explained more variance in the data. Although the present experiments were not designed to answer this question, we attempted to address this issue via regression analyses. We used the latencies of the first presentation of Experiment 2 as dependent variable and three predictors - frequency, familiarity ratings, and imageability ratings. The analyses were done separately on the data of the FM-matched condition and of the FM-confounded condition. In the FM-matched list condition, when frequency was entered first in the model, the explained variance was $17.6 \%\left[F(1,40)=8.56, M S_{\mathrm{e}}=\right.$ $1,640.49, p<.006]$, and the addition of familiarity or imageability did not produce a significant increase $(F<1)$. In the FM-confounded list condition, the addition of familiarity to the model in which frequency was entered first produced a $36 \%$ increase in the variance accounted for $[F(1,39)=36.75, p<.001]$, whereas the addition of imageability was not significant $(F<1)$. The same pattern occurred when imageability was entered immediately after frequency in the model — that is, there was no significant contribution of either imageability or familiarity in the FM-matched list, and there was only a significant contribution of familiarity in the FM-confounded list. Table 9 displays the correlations among the four variables. Thus, the data suggest that, in the present study and with the present stimuli, the frequency reduction was mainly due to familiarity. Perhaps a stronger manipulation of imageability might produce a different pattern. However, because unspeeded familiarity ratings may include both familiarity and imageability components (see Balota et al., 2001, and Gernsbacher, 1984, for discussions), it is not surprising that familiarity is picking up the largest portion of the variance in lexical decision.

The data for words in the lexical decision task also show a frequency $\times$ repetition priming interaction, suggesting that many low-frequency words are able to pass the fast criterion when these items are presented a second time. However, this interaction, albeit reduced, was present also in the FM-matched list, showing that although low-frequency words were matched for FM, they still received a larger advantage from repetition than did highfrequency words. This suggests that the repetition effect did not entirely depend on the mechanism evaluating the global familiarity of stimuli but also depended in part on other factors. One of these factors is frequency. Although low-frequency words were matched for familiarity, they were still less frequent than the high-frequency words. If frequency, as instantiated in the norms, reflects primarily the number of times an orthographic sequence has been encountered, the greater advantage for low-frequency words can be explained as an increase in activation level of these representations.

The second mechanism sensitive to repetition, as noted above, is related to the retrieval of the episodic trace. This could involve a stimulus-response integration process,

\begin{tabular}{|c|c|c|c|c|}
\hline \multicolumn{5}{|c|}{$\begin{array}{c}\text { Table } 9 \\
\text { Correlations Between Variables for the Data } \\
\text { of the First Presentations (First Block) of the Stimuli } \\
\text { in the FM-Matched and FM-Confounded Conditions } \\
\text { in Experiment } 2\end{array}$} \\
\hline & LD RT & WF & Familiarity & Imageability \\
\hline \multicolumn{5}{|c|}{ FM-Matched Condition } \\
\hline $\begin{array}{l}\text { LD RT } \\
\text { WF } \\
\text { Familiarity } \\
\text { Imageability }\end{array}$ & 1.00 & $\begin{array}{r}-.42 \\
1.00\end{array}$ & $\begin{array}{r}-.23 \\
.23 \\
1.00\end{array}$ & $\begin{array}{l}-.006 \\
-.25 \\
.66 \\
1.00\end{array}$ \\
\hline \multicolumn{5}{|c|}{ FM-Confounded Condition } \\
\hline $\begin{array}{l}\text { LD RT } \\
\text { WF } \\
\text { Familiarity } \\
\text { Imageability }\end{array}$ & 1.00 & $\begin{array}{r}-.51 \\
1.00\end{array}$ & $\begin{array}{r}-.79 \\
.61 \\
1.00\end{array}$ & $\begin{array}{r}-.28 \\
.25 \\
.23 \\
1.00\end{array}$ \\
\hline
\end{tabular}

Note-FM, familiarity/meaningfulness; LD RT, lexical decision response time; WF, written frequency.

as proposed by Logan (1990). In this light, a comparison of the results from Experiments 1 and 2 is useful. Specifically, when repetition occurred within a list (Experiment 1) and included shorter lags, as opposed to across lists (Experiment 2), there was an increase in the size of the repetition effect, as reflected by larger priming effects in Experiment 1 than in Experiment $2\left[F_{1}(1,142)=\right.$ $5.22, M S_{\mathrm{e}}=2,003.24, p<.05 ; F_{2}(1,80)=12.23, M S_{\mathrm{e}}=$ $503.31, p<.01]$. This likely reflects the influence of relatively recent episodic exposure in the mixed repetition list condition than in the blocked repetition condition.

The data for the nonwords are also intriguing here. Specifically, as shown in Figure 1, we predicted that the nonwords would overlap more with the low-frequency words in the FM-confounded condition than in the FMmatched condition. Hence, RTs to the nonwords should be faster in the FM-matched condition. Although this pattern did occur in Experiment 2, in which repetitions were not intermixed within the list, this pattern was not obtained in Experiment 1. This may suggest that the participants relied more on episodic retrieval in Experiment 1 than in Experiment 2 in making their decisions, because the lags were considerably shorter in the former experiment. This information would have speeded overall RTs, and, in fact, this is what was found $\left[F_{1}(1,142)=9.66, M S_{\mathrm{e}}=\right.$ $35,459.62, p<.01 ; F_{2}(1,41)=151.57, M S_{\mathrm{e}}=2,509.98$, $p<.001]$. Hence, the argument would be that the participants used additional information beyond FM values to discriminate words from nonwords, especially when such information was particularly salient, as in the intermixed and short-lag conditions of Experiment 1.

Of course, one might ask why one finds large facilitatory effects of repetition for the nonwords, since repetition should produce a boost in FM values for these items and hence make these items difficult to reject. As noted in the introduction, this is consistent with arguments by Zeelenberg et al. (2004) and Balota and Spieler (1999), who suggest that there are multiple loci for repetition effects. When the stimulus, decision, and response are repeated, one should find facilitatory effects. This is consistent 
with the present results. However, when one only affords a change in the FM value, by changing the task across repetitions, then one finds inhibitory effects. Again, this is consistent with the results of Zeelenberg et al. (2004) and Balota and Spieler (1999).

Given the intriguing effects of repetition, this work has some intriguing implications for research on recognition memory performance, wherein distinctions between recollection and familiarity play a dominant role in memory theory (see Yonelinas, 2002). For example, there is evidence of a mirror word-frequency effect in episodic memory performance (see Glanzer \& Adams, 1990). Specifically, hit rates are higher for low-frequency words than for high-frequency words, whereas false alarm rates are higher for high-frequency words than for low-frequency words. A two-process account for this mirror pattern suggests that low-frequency words produce the advantage in hit rates due to higher recollection of these items over high-frequency words, and this outweighs the greater familiarity afforded by the high-frequency items (see, e.g., Joordens \& Hockley, 2000). On the other hand, in the absence of recollection, the higher false alarm rate for high-frequency words over low-frequency words is due to participants' responding on the basis of baseline familiarity. Given the present dissociation between frequency and FM, it would be useful to extend this work to recognition memory performance to determine whether one could isolate the role of each of these variables.

There is an alternative account of the isolable influences of frequency and familiarity that should also be mentioned. Specifically, one could argue that the reason one obtains a larger frequency effect in the FM-confounded condition is simply due to the fact that objective frequency norms have considerable error associated with them and familiarity estimates are a better measure of true frequency. Hence, the FM-confounded condition includes a larger manipulation of frequency than does the FM-matched condition. If this were the case, then one would have expected a larger frequency effect in the FM-confounded condition than in the FM-matched condition in naming also. However, neither experiment provided any hint of such a pattern in naming performance. Thus, it appears, we were successful in dissociating FM values from objective frequency.

One might ask whether these results would extend to a different language, such as English. Fortunately, we have an access to a large database, so that we can address this possibility. This database was taken from Balota, Cortese, Sergent-Marshall, Spieler, and Yap (2004), who listed lexical decision and naming RTs for 2,342 singlesyllable words from two independent groups of participants. Regression analyses were conducted to determine whether FM measures predicted more variance in lexical decision than in naming performance after frequency and other variables were partialled out. Hence, as described by Balota et al., we used a hierarchical regression model in which we partialled out phonological onset variables in Step 1, length, orthographic $N$, four spelling-to-sound and sound-to-spelling consistency measures in Step 2, log word frequency in Step 3, and familiarity and imageabil- ity in Step 4. The results clearly converged with the present conclusions. Specifically, there was an increment in $R^{2}$ of .126 in lexical decision in Step 4, whereas there was an increment of only .008 in naming in Step 4. Although both increments were reliable, the 15 times greater increase in $R^{2}$ estimate in Step 4 in lexical decision, relative to naming, clearly converges on the present argument that these two tasks are differentially sensitive to familiarity/ imageability, above and beyond frequency and other variables related to performance in these two tasks.

Finally, it should be noted that frequency interacted with repetition in naming, and this result is intriguing in light of Balota and Spieler's (1999) failure to obtain such an interaction in naming. As already noted, however, they used a rhyming task for the first presentation of the stimuli, and so the specific processes involved in mapping the orthographic code onto a speech output were not repeated in their study. The attenuation of the frequency effect with repetition may be located at the level of accessing orthographic representations (Barry, Hirsh, Johnston, \& Williams, 2001) and/or in the attenuation of the frequency effect in output processes. It should also be noted that, in the present study, frequency effects in naming were very robust and reliable, despite the familiarity manipulation and although the language in which the words were presented was regular in spelling-sound correspondence (but see Colombo, 1992; Colombo \& Tabossi, 1992). Ultimately, the present results clearly emphasize the important role of both frequency and meaningfulness in modulating lexical decision performance.

\section{REFERENCES}

ANDREws, S. (1982). Phonological recoding: Is the regularity effect consistent? Memory \& Cognition, 10, 565-575.

Andrews, S., \& Heathcote, A. (2001). Distinguishing common and task-specific processes in word identification: A matter of some moment? Journal of Experimental Psychology: Learning, Memory, \& Cognition, 27, 514-544.

Balota, D. A., \& Chumbley, J. I. (1984). Are lexical decisions a good measure of lexical access? The role of word frequency in the neglected decision stage. Journal of Experimental Psychology: Human Perception \& Performance, 10, 340-357.

BAlota, D. A., \& Chumbley, J. I. (1985). The locus of word-frequency effects in the pronunciation task: Lexical access and/or production? Journal of Memory \& Language, 24, 89-106.

Balota, D. A., Cortese, M. J., Sergent-Marshall, S. D., Spieler, D. H., \& YAP, M. J. (2004). Visual word recognition of single-syllable words. Journal of Experimental Psychology: General, 133, 283-316.

Balota, D. A., \& Ferraro, F. R. (1996). Lexical, sublexical, and implicit memory processes in healthy young and healthy older adults and in individuals with dementia of Alzheimer type. Neuropsychology, 10, 82-95.

Balota, D. A., Pilotti, M., \& Cortese, M. J. (2001). Subjective frequency estimates for 2,938 monosyllabic words. Memory \& Cognition, 29, 639-647.

Balota, D. A., \& Spieler, D. H. (1999). Word frequency, repetition, and lexicality effects in word recognition tasks: Beyond measures of central tendency. Journal of Experimental Psychology: General, 128, 32-55.

Barca, L., Burani, C., \& Arduino, L. S. (2002). Word naming times and psycholinguistic norms for Italian nouns. Behavior Research Methods, Instruments, \& Computers, 34, 424-434.

Barry, C., Hirsh, K. W., Johnston, R. A., \& Williams, C. L. (2001). Age of acquisition, word frequency, and the locus of repetition priming of picture naming. Journal of Memory \& Language, 44, 350-375. 
BECKER, C. A. (1979). Semantic context and word frequency effects in visual word recognition. Journal of Experimental Psychology: Human Perception \& Performance, 5, 252-259.

Besner, D., \& Swan, M. (1982). Models of lexical access in visual word recognition. Quarterly Journal of Experimental Psychology, 34A, 313-325.

Bodner, G. E., \& Masson, M. E. J. (1997). Masked repetition priming of words and nonwords: Evidence for a nonlexical basis for priming. Journal of Memory \& Language, 37, 268-293.

Borowsky, R., \& BeSner, D. (1993). Visual word recognition: A multistage activation model. Journal of Experimental Psychology: Learning, Memory, \& Cognition, 19, 813-840.

Colombo, L. (1992). Lexical stress effect and its interaction with frequency in word pronunciation. Journal of Experimental Psychology: Human Perception \& Performance, 18, 987-1003.

Colombo, L., \& TAвossi, P. (1992). Strategies and stress assignment: Evidence from a shallow orthography. In R. Frost \& L. Katz (Eds.) Orthography, phonology, morphology, and meaning (pp. 319-340) Amsterdam: Elsevier.

Coltheart, M., Rastle, K., Perry, C., Langdon, R., \& Ziegler, J. (2001). DRC: A dual route cascaded model of visual word recognition and reading aloud. Psychological Review, 108, 204-256.

DucheK, J. M., \& NeELY, J. H. (1989). A dissociative word-frequency $\times$ levels-of-processing interaction in episodic recognition and lexica decision tasks. Memory \& Cognition, 17, 148-162.

Feustal, T. C., Shiffrin, R. M., \& Salasoo, A. (1983). Episodic and lexical contributions to the repetition effect in word identification Journal of Experimental Psychology: General, 112, 309-346.

Forbach, G. B., Stanners, R. F., \& Hochhaus, L. (1974). Repetition and practice effects in a lexical decision task. Memory \& Cognition, 2, 337-339.

Forster, K. I. (1976). Accessing the mental lexicon. In R. J. Wales \& E. Walker (Eds.), New approaches to language mechanisms: A collection of psycholinguistic studies (pp. 257-287). Amsterdam: NorthHolland.

Forster, K. I., \& Chambers, S. M. (1973). Lexical access and naming time. Journal of Verbal Learning \& Verbal Behavior, 12, 627-635.

Forster, K. I., \& DAVIS, C. (1984). Repetition priming and frequency attenuation in lexical access. Journal of Experimental Psychology. Learning, Memory, \& Cognition, 10, 680-698.

GeRnsBaCHER, M. A. (1984). Resolving 20 years of inconsistent interactions between lexical familiarity and orthography, concreteness, and polysemy. Journal of Experimental Psychology: General, 113, 256-281.

Glanzer, M., \& AdAms, J. K. (1990). The mirror effect in recognition memory: Data and theory. Journal of Experimental Psychology: Learning, Memory, \& Cognition, 16, 5-16.

Grainger, J., \& JACOBS, A. M. (1996). Orthographic processing in visual word recognition: A multiple read-out model. Psychological Review, 103, 518-565.

Istituto di Linguistica Computazionale del CNR di Pisa (1989). Corpus di Italiano scritto contemporaneo [Corpus of contemporary written Italian]. Unpublished manuscript.

JACOBY, L. L., \& DALlas, M. (1981). On the relationship between autobiographical memory and perceptual learning. Journal of Experimental Psychology: General, 110, 306-340.

JoORdENS, S., \& HocKLEY, W. E. (2000). Recollection and familiarity through the looking glass: When old does not mirror new. Journal of Experimental Psychology: Learning, Memory, \& Cognition, 26, 1534-1555.

Logan, G. D. (1988). Toward an instance theory of automatization. Psychological Review, 95, 492-527.
Logan, G. D. (1990). Repetition priming and automaticity: Common underlying mechanisms? Cognitive Psychology, 22, 1-35.

MCCANN, R. S., \& BESNER, D. (1987). Reading pseudohomophones: Implications for models of pronunciation assembly and the locus of word frequency effects in naming. Journal of Experimental Psychology: Human Perception \& Performance, 13, 14-24.

MCCANN, R. S., BeSner, D., \& DAVElaAR, E. (1988). Word recognition and identification: Do word-frequency effects reflect lexical access? Journal of Experimental Psychology: Human Perception \& Performance, 14, 693-706.

McClelland, J. L., \& Rumelhart, D. E. (1981). An interactive activation model of context effects in letter perception: Part 1. An account of basic findings. Psychological Review, 88, 375-407.

McRae, K., Jared, D., \& Seidenberg, M. S. (1990). On the roles of frequency and lexical access in word naming. Journal of Memory \& Language, 29, 43-65.

Monsell, S., Doyle, M. C., \& Haggard, P. N. (1989). Effects of frequency on visual word recognition tasks: Where are they? Journal of Experimental Psychology: General, 118, 43-71.

MorTon, J. (1979). Facilitation in word recognition: Experiments causing change in the logogen model. In P. A. Kolers, M. E. Wrolstad, \& H. Bouma (Eds.), Processing of visible language: Vol. 1 (pp. 259268). London: Plenum.

Murray, W. S., \& Forster, K. I. (2004). Serial mechanisms in lexical access: The rank hypothesis. Psychological Review, 3, 721-756.

PaAp, K. R., McDonald, J. E., Schvaneveldt, R. W., \& Noel, R. W. (1987). Frequency and pronounceability in visually presented naming and lexical-decision tasks. In M. Coltheart (Ed.), Attention and performance XII: The psychology of reading (pp. 221-244). Hillsdale, NJ: Erlbaum.

Paap, K. R., Newsome, S. L., McDonald, J. E., \& Schvaneveldt, R. W. (1982). An activation-verification model for letter and word recognition: The word-superiority effect. Psychological Review, 89, 573-594.

Plaut, D. C. (1997). Structure and function in the lexical system: Insights from distributed models of word reading and lexical decision. Language \& Cognitive Processes, 12, 765-806.

Plaut, D. C., McClelland, J. L., Seidenberg, M. S., \& Patterson, K. (1996). Understanding normal and impaired word reading: Computational principles in quasi-regular domains. Psychological Review, 103, 56-115.

Scarborough, D. L., Cortese, C., \& Scarborough, H. S. (1977). Frequency and repetition effects in lexical memory. Journal of Experimental Psychology: Human Perception \& Performance, 3, 1-17.

SeidenberG, M. S., \& McClelland, J. L. (1989). A distributed, developmental model of word recognition and naming. Psychological Review, 96, 523-568.

Toglia, M. P., \& Battig, W. F. (1978). Handbook of semantic word norms. Hillsdale, NJ: Erlbaum.

Wagenmakers, E.-J., Steyvers, M., Raaijmakers, J. G. W., ShifFrin, R. M., van Rijn, H., \& Zeelenberg, R. (2004). A model for evidence accumulation in the lexical decision task. Cognitive Psychology, 48, 332-367.

Wagenmakers, E.-J., Zeelenberg, R., Steyvers, M., Shiffrin, R. M., \& RAAIJMAKERS, J. G. W. (2004). Nonword repetition in lexical decision: Support for two opposing processes. Quarterly Journal of Experimental Psychology, 57A, 1191-1210.

Yonelinas, A. P. (2002). The nature of recollection and familiarity: A review of 30 years of research. Journal of Memory \& Language, 46, 441-517.

Zeelenberg, R., Wagenmakers, E.-J., \& Shiffrin, R. M. (2004). Nonword repetition priming in lexical decision reverses as a function of study task and speed stress. Journal of Experimental Psychology: Learning, Memory, \& Cognition, 30, 270-277. 
APPENDIX

List of Word Stimuli

\begin{tabular}{|c|c|}
\hline $\begin{array}{l}\text { High Frequency-FM Matched } \\
\text { albergo } \\
\text { argento } \\
\text { carcere } \\
\text { cinema } \\
\text { colore } \\
\text { compagno } \\
\text { denaro } \\
\text { diavolo } \\
\text { famiglia } \\
\text { marito } \\
\text { natura } \\
\text { ospite } \\
\text { palazzo } \\
\text { parola } \\
\text { principe } \\
\text { provincia } \\
\text { ragazzo } \\
\text { silenzio } \\
\text { stagione } \\
\text { sorella }\end{array}$ & $\begin{array}{l}\text { High Frequency-FM Confounded } \\
\text { carcere } \\
\text { cimitero } \\
\text { cinema } \\
\text { denaro } \\
\text { dramma } \\
\text { finestra } \\
\text { fiume } \\
\text { furto } \\
\text { gente } \\
\text { gruppo } \\
\text { guerra } \\
\text { marito } \\
\text { ministro } \\
\text { moglie } \\
\text { mondo } \\
\text { natura } \\
\text { ospedale } \\
\text { ragazzo } \\
\text { riva } \\
\text { ufficio } \\
\text { vino }\end{array}$ \\
\hline $\begin{array}{l}\text { Low Frequency-FM Matched } \\
\text { alunno } \\
\text { befana } \\
\text { bibita } \\
\text { confetto } \\
\text { cuscino } \\
\text { fantasma } \\
\text { furgone } \\
\text { femmina } \\
\text { incubo } \\
\text { insetto } \\
\text { mandorla } \\
\text { matita } \\
\text { padella } \\
\text { parrucca } \\
\text { patata } \\
\text { pettine } \\
\text { pomata } \\
\text { racchetta } \\
\text { sciroppo } \\
\text { zanzara }\end{array}$ & $\begin{array}{l}\text { Low Frequency-FM Confounded } \\
\text { alluce } \\
\text { anguilla } \\
\text { baco } \\
\text { batuffolo } \\
\text { biscia } \\
\text { brodo } \\
\text { bugia } \\
\text { cipresso } \\
\text { fata } \\
\text { febbre } \\
\text { fieno } \\
\text { geranio } \\
\text { ghiro } \\
\text { guaio } \\
\text { litigio } \\
\text { manzo } \\
\text { orma } \\
\text { ortica } \\
\text { sillaba } \\
\text { tatto } \\
\text { usignolo }\end{array}$ \\
\hline
\end{tabular}

(Manuscript received February 8, 2005;

revision accepted for publication August 5, 2005.) 